\title{
HIJRAH MILENIAL: ANTARA KESALEHAN DAN POPULISM
}

\author{
Firly Annisa, MA.
}

\section{Abstrak}

Publik Islam yang pada rezim sebelumnya dikontrol dalam ruang keagamaan formal agar mudah dikendalikan oleh negara, pada era Reformasi mulai menyebar pada kepemimpinan organisasi masyarakat dan politik praktis. Hadirnya berbagai partai politik yang menggunakan Islam sebagai basis dan symbol politik menjadi petanda "kebangkitan" Islam dalam ruang demokrasi. Apabila dihubungkandengan tumbuhnya media social dan jaringan internet di Indonesia, micro celebrities menjadi komponen penting menghadirkan identitas Islam dalam budaya populer. Dengan menarik pengikut di media social Instagram, para micro-celebrities Muslim, dapat berpotensi membentuk "Publik Islam" mereka sendiri. Dengan mengelola wacana kesalehan melalui performativitas tubuh yang diunggah secara terus menerus di media sosial, publik Islam dapat terbentuk dengan berbagai tujuan seperti menggaet popularitas yang berujung pada keuntungan ekonomi dan popularitas. Penyebaran otoritas pengetahuan semakin terjadi dalam segmen-segmen kecil, yang justru sulit dikontrol dan justru dapat menjadi embrio radikalisme, fanatisme dan intoleransi karena hanya menghadirkan hitam putih agama yang sekali lagi miskin argumentasi dan kontemplasi.

Kata kunci: micro celebrities, kesalehan, hijrah, media sosial, Instagram, identitas 


\section{Pendahuluan}

Euforia identitas agama [Islam] berkembang secara masif pasca Reformasi 1998. Fakta ini terlihat dengan digunakannya Islam sebagai kendaraan untuk memperoleh simpati dan empati kepada publik. Publik Islam pada masa Orde Baru dikontrol dalam ruang keagamaan formal ${ }^{1}$ agar mudah dikendalikan oleh negara, justru pada era Reformasi mulai menyebar pada kepemimpinan organisasi masyarakat dan politik praktis. Menurut Qodir ${ }^{2}$ kebangkitan Islam dalam ruang demokrasi ditandai dengan hadirnya berbagai partai politik yang menggunakan Islam sebagai basis dan simbol politik. Meskipun pada era sebelumnya partai Islam sudah pernah berdiri, namun terdapat konteks politik, sosial dan budaya yang sangat berbeda dengan kondisi partai politik Islam hari ini. Lebih kurang pada era Reformasi, Publik Islam kemudian dijadikan arena perebutan kekuasaan, oleh karenanya sangat penting mengambil suara mereka dalam pemilu. Dalam konteks budaya populer dan media sosialhari ini, microcelebrities ternyata juga mengambil peranan dalam pembentukan publik Islam.

Apabila dihubungkan dengan tumbuhnya media sosial dan jaringan internet di Indonesia, micro-celebrities menjadi komponen penting menghadirkan identitas Islam dalam budaya populer. Itulah mengapa dalam ruang media baru, Lewis ${ }^{3}$ menjelaskan micro-celebrities tidak hanya sebagai style-mediator, tetapi juga spiritual advisor. Dengan menarik pengikut di media sosial Instagram, para micro-celebrities Muslim, dapat berpotensi membentuk "Publik Islam” mereka sendiri. Merujuk pada Noorhaidi ${ }^{4}$ dan Zachary ${ }^{5}$ publik Islam adalah sekelompok warga yang dapat menunjukkan praktik agama dalam ruang publik. Praktik agama tidak hanya dalam ritual namun juga ekspresi politik, transaksi resmi, aktivitas ekonomi, praktik sosial dan budaya dalam kehidupan sehari-hari. Publik Islam ini juga akan cenderung bersikap positif terhadap implementasi atas hukum Islam atau biasa disebut syariah Islam.

1 Carool Kersten, Islamic Post-Traditionalism: Postcolonial and Postmodern Religious Discourse in Indonesia. (Springer Science, Business Media Dordrecht, 2014), hal. 476.

2 Zuly Qodir, "Public Sphere Contestation: Configuration of Political Islam in Contemporary Indonesia" dalam IJIMS, Indonesian Journal of Islam and Muslim Societies Vol. 1, No. 1 (2011), hal. 124.

3 Reiana Lewis, Modest Fashion. (London: I.B. Tauris, 2013), hal. 50.

4 Noorhaidi Hasan, The Making of Public Islam: Piety, Agency, and Commodification on the Landscape of the Indonesian Public Sphere. (Netherlands: Springer, 2009), hal. 236-237

5 Zachary Abuza, Political Islam and violence in Indonesia. (London: Routledge, 2007), hal. 174175 
Mengacu pada Raun ${ }^{6}$ Micro-celebrities akan selalu memastikan kedekatan dan keintiman cerita pribadi di ruang publik. Keintiman ini menjadi daya tarik dalam setiap cerita, gambar, dan caption yang mereka unggah dalam ruang maya atau disebut juga cyberspace. Untuk dekat dan disenangi oleh pengguna media sosial, Micro-celebrities harus memberi sinyal aksesibilitas (kemudahan mengakses internet), kehadiran citra mereka secara berkesinambungan dalam dunia maya, keterhubungan dengan penggemar, dan yang paling penting "keaslian" atas tampilan diri. Hal tersebut bertujuan untuk membentuk keintiman yang dibangun terus menerus dengan pengikut mereka di dunia maya.mTurut ditegaskan oleh Baym $^{7}$ dan Boyd ${ }^{8}$, ruang maya mengaburkan antara posisi penerima dan pengirim pesan, begitu pula mengenai definisi waktu dan ruang, kontrol dan kebebasan, hingga persoalan pribadi atau publik.

Lebih lanjut keadaan ini mengubah bentuk-bentuk interaksi sehingga disebut terjadinya peristiwa "socially mediated publicness". Situasi ini terjadi ketika media sosial berfungsi sebagai refleksi, ia menjadi perantara mediasi publik terhadap persoalan sosial. Dapat dikatakan pula publik dapat"melihat" aspek kehidupan sehari-hari yang multi dimensi melalui mediasi atau perantara ruang dunia maya. Sehingga cyberspace dapat disebut ruang di mana fenomena sosial "diperebutkan" untuk ditampilkan dan dibincangkan, agar dianggap penting untuk mewakili masalah publik. Tentu saja dengan demikian ruang dunia maya akan dapat bersifat politis. Dunia maya bukan lagi ruang hampa yang tidak bertuan, namun penuh dengan kontestasi pengaruh, eksistensi dan kekuasaan.

\section{Media Sosial Instagram dan Generasi Milenial}

Sebagai negara Muslim terbesar di dunia, industrialisasi pasar Islam di Indonesia tidak dapat terelakkan. Dalam posisi ini figur anak muda dalam publik Islam menjadi bagian penting. Mereka adalah aktor-aktor yang membuat pasar Islam di Indonesia berjalan menguntungkan secara ekonomi politik. Dalam konteks di Indonesia setelah bergulirnya era Reformasi, dengan secara sadar atas menguatnya wacana Islam, micro-celebrities turut menumpang berbagai identitas

6 Tobias Raun, Capitalizing intimacy: "New subcultural forms of micro- celebrity strategies and affective labor on YouTube" dalam Convergence: The International Journal of Research into New Media Technologies, Vol. 24, No. 1 (London: Sage Publication, 2018), hal. 99-113.

7 Baym Nancy. K,Personal Connections in the DigitalAge. (London: Polity, 2010), hal. 2-4

8 Boyd Danah, "Social NetworkSites as NetworkedPublics: Affordances, Dynamics, and Implications"dalam A Networked Self: Identity, Community And Culture On Social Network Sites,eds. Zizi Papacharissi. (New York: Routledge, 2010), hal. 39-58

9 Baym Nancy K., \& Boyd Danah, Socially Mediated Publicness: An Introduction, Journal of Broadcasting \&Electronic Media Vol.56, No.3 (2012), hal. 320-329. 
Muslim tersebut. Dengan mengelola wacana kesalehan melalui performativitas tubuh yang diunggah secara terus-menerus di media sosial, publik Islam dapat terbentuk dengan berbagai tujuan seperti menggaet popularitas yang berujung pada keuntungan ekonomi. Lalu siapakah aktor-aktor yang aktif merebutkan ruang yang sangat "cair" ini? Tidak lain adalah pihak-pihak yang melek teknologi, memiliki kemampuan mengelola pesan dengan cemerlang dan memahami isuisu terkini.

Di sinilah generasi milenialdan generasi $\mathrm{Z}$ mengambil peran. Realitas yang terjadi dalam rentang waktu tahun 2015-2025 usia produktif di dunia tidak terkecuali di Indonesia, mulai dijalankan oleh generasi Milenial atau generasi Y. Milenial adalah mereka generasi yang lahir pada era 1980-1999, era di mana mereka hidup melewati milenium kedua. Pada tahun 2018 ini mereka adalah anak-anak muda berisi paling tua 37-38 tahun dan yang paling muda 24 tahun. Pada era ini selain generasi Milenial, hiduplah anak-anak dan remaja pada usia 14-23 tahun atau yang disebut Gen-Z. Generasi yang lahir setelah tahun 2000-an ini merupakan konsumen yang sangat potensial dan bersiap berkompetisi dengan generasi Milenial setidaknya pada kurun waktu dua tahun lagi. Menurut survey Nielsen Consumer \& Media View (CMV) ${ }^{10}$ kuartal II 2016 yang di lakukan di 11 kota Indonesia, generasi $\mathrm{Z}$ ini sangat memperhitungkan pembelian teknologi dan suka sekali melakukan traveling. Hobi mereka yang suka berpergian ini akan sejalan dengan cara mengabadikan pengalaman mereka melalui teknologi visual di media sosial. Eksistensi dalam politik ruang maya akan lebih terasa ketika generasi Y dan $\mathrm{Z}$ ini menjadikan latar belakang foto-foto mereka ketika berpergian sebagai bagian dari pencitraan dan eksistensi diri.

Konsekuensi dari berbagai aplikasi media sosial yang menerpa generasi Milenial dan generasi $\mathrm{Z}$ menjadikan salah satu lahirnya generasi yang menyukai kepraktisan dan kecepatan dalam belajar, bekerja, bahkan pada persoalan mengonsumsi gaya hidup. Generasi ini akan lebih mempertimbangkan tempat liburan dan hiburan yang unik untuk di foto dan diunggah di media sosial contohnya Instagram atau lebih di kenal dengan istilah Instagramable. Begitu pula dalam diskursus agama [Islam], kemudahan melakukan klik berita berlabel Islam, pengajian online, termasuk menjadi pengikut setia akun-akun berlabel ustad $z$ atau ulama gaul tidak dapat lagi terelakkan. Informasi mengenai larangan berpacaran hingga informasi mengenai hijrah sekarang sedang menjadi tren kaum muda urban karena tersaji dalam visualitasyang indah, praktis sekaligus renyah diproduksi dan dinikmati dua generasi produktif ini.

10 http://www.nielsen.com/id/en/press-room/2016/GEN-Z-KONSUMEN-POTENSIAI-MASA-DEPAN. html 
Dalam penelitian terbaru yang dirilis oleh Alvara Research Center ${ }^{11}$ mengenai sembilan perilaku milenial Indonesia menunjukkan fakta satu dari tiga penduduk Indonesia adalah Milenial dan delapan dari sepuluh generasi milenial terkoneksi dengan internet. Menariknya 40,1\% generasi Mileneal memiliki akun Instagram. Dengan menggunakan tampilan dan pakaian masa kini, bahasa ringan, dan atribut-atribut budaya Muslim menjadikan label ustadz dan ulama sangat mudah dijumpai dalam media sosial Instagram. Pada akhirnya visualitas yang menarik, video pendek, caption motivasi berbuat baik, reproduksi mengenai "ketaatan" dapat mudah dijumpai dalam genggaman tangan.

Kata kunci cyber-culture adalah visualitas. Merujuk pada Nicholas Mirzoeff ${ }^{12}$ visualitas adalah bagian dari informasi, makna atau kenikmatan bersumber pada konsumsi teks yang menggunakan teknologi visual seperti telepon pintar. Visualitas bukan pada pandangan yang alami namun telah dimediasi oleh seperangkat media. Pada konteks ini keindahan gambar menjadi unsur utama yang mewakili peristiwa tertentu karena kenikmatan pandangan menjadi kunci pada budaya visual yang sebenarnya dapat tidak berarti apapun alias banal. Orang-orang yang disebut "ulama" ini tidak bekerja sendirian, berpengaruhnya posisi mereka dalam masyarakat saat ini juga karena kerja media. Di sinilah Micro-celebrities melalui kemampuan mengelola media sosial mampu menjadi agen bagi dirinya sendiri untuk melakukan konstruksi mengenai definisi hijrah.

Namun karena keterikatan dengan teknlogi yang sesungguhnya juga terbatas daripada interaksi langsung, tidak dapat terhindarkan konstruksi hijrah akan dapat sangat bias kepentingan. Banalitas budaya visual dapat tercipta apabila pengguna media tidak dapat menjumpai persamaan konteks antara kehidupan dirinya yang nyata dengan konteks pada dunia maya. Kondisi ketidaksamaan konteks tersebut melahirkan kegagalan proses memaknai. Proses memaknai menjadi kabur, dan pada akhirnya pengguna akan kesulitan mengidentifikasi realitas asli dengan yang palsu. Meminjam istilah simulacra oleh Baudriliard ${ }^{13}$ kekaburan tersebut tampak ketika dunia maya menyediakan simulasi atas dunia nyata yang tampak lebih asli dari kenyataan itu sendiri. Dunia maya menjadi simulasi-simulasi kehidupan yang bisa saja kehidupan itu tidak berharga bahkan tidak ada pada dunia nyata.

11 www.alvara-strategic.com diakses pada 15 Agustus 2018

12 Nicholas Mirzoeff, An Introduction to Visual Culture (UK: Taylor\&Francis Ltd, 1999). hal.43

13 Jean Baudrillard, The Precession of Simulacra dalam Media and Cultural Studies: Keyworks,eds. Meenakshi Gigi Durham and Douglas M. Kellner (eds). (Malden, Massachusetts: Blackwell Publishing, 2006), hal. 134. 


\section{Hijrah Online: Rajin Mengaji hingga Budaya Konsumsi}

Di Indonesia kita dapat menghubungkannya dengan fenomena hari ini, dengan lahirlah apa yang dinamakan "ulama online". Ulama yang bisa dikategorikan micro-celebrities salah satunya Hanan Attaki. Ia memperkenalkan terminologi hijrah melalui kajian yang ia sebarkan melalui media sosial seperti Youtube dan Instagram. Menggunakan tampilan topi ala musim dingin Eropa, bermain papan seluncur atau biasa disebut skateboard, dan berjaket hodies, pengikut Instagram Hanan Attaki dalam akunnya bernama @hanan_attaki sampai bulan Agustus 2018 ini telah mencapai empat juta followers. Semakin populernya di kalangan muda Milenial, ia bahkan disebut sebagai ustadznya kaum jomblo ${ }^{14}$. Seperti yang disampaikan oleh Susie, Lawrence dan Raymond", "Social media is driven by a specific kind of identity construction - self-mediation - and what users post, share and like effectively creates a highly curated and often a bridged snapshot of how they want to beseen". "Ulama Milenial" pendiri komunitas

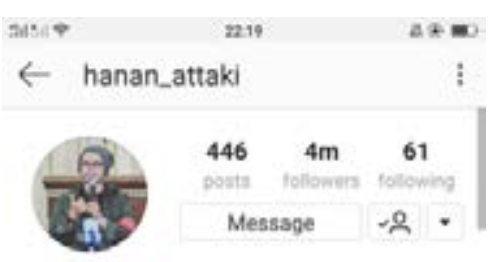

Founder SHIFT @pemudahijrah

Motivational Speaker

Alumni Al-Azhar Kairo 2004

Suami yg beruntung

Ayah yg bahagia

Teman yg suka ngopi

'Banyak maen, banyak manfaat, banysk pahala sedkit dosa.."

SEE TRANSLATION

bitlly/HananAttakiChannel

Jalan Saninten No. 2, Bandung

followed by tokorends46 venna syifss vekadnahman

+77 more

Directions

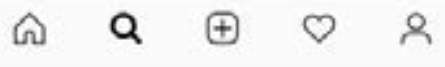

Gambar 1. Profil akun Instagram Hanan Attaki

bernama SHIFT dengan akun Youtube dan

Instagram bernama@pemudahijrahini konsisten mengkampanyekan nikmatnya nikah muda, pertobatan dalam kehidupan, dan motivasi-motivasi hidup yang diklaim sesuai ayat-ayat Al-Qur'an.

Produksi pengetahuan agama, dioperasikan melalui bahasa-bahasa yang telah dipilih sedemikian rupa bertujuan untuk mengkonstruksikan citra diri. Wacana merupakan bagian dari pengetahuan dibentuk berdasarkan relasi kuasa. Hijrah online pada media sosial dapat dilihat sebagai relasi kuasa, pihak-pihak yang dapat mengimplementasikan marketing branding, dengan seperangkat pesan komunikasi yang menarik dan efisien. Bagaimana makna

14 Subkhi Ridho,"Identitas Kelas Menengah Muslim di Media Sosial: Studi terhadap Wacana Islam di Media Sosial (Instagram dan Twitter)" dalam Anne Shakka Ariyani dan A. Harimurti (eds.) Nasionalisme Di Tengah Kewargaan Budaya dan Ekstremisme Global, Yogyakarta: PuSdEP, 2018. hal. 433-454.

15 Susie Khamis, Lawrence Ang\& Raymond Welling. "Self-branding, 'micro-celebrity' and the rise of Social Media Influencers" dalam Celebrity Studies, Vol.8, No. 2, (UK: Routledge), hal.196. 
hijrah dikonstruksikan kemudian menjadi menarik karena berkaitan dengan wacana agama dan posisi anak muda dalam masyarakat. Melalui media sosial anak muda kemudian digambarkan sebagai entitas yang perlu diarahkan, diberi petunjuk karena mereka dianggap belum siap dalam mengambil keputusan. Namun juga sebaliknya, kaum muda adalah pihak yang dianggap mudah didekati dengan segala hal yang berbau instan. Konstruksi mengenai anak muda tersebut dihadapkan dengan nilai-nilai yang seakan-akan datang dari budaya "Barat" yang dianggap akan mudah merusak generasi muda seperti wacana mengenai liberalisme dan kapitalisme. Melalui kemudahan teknologi, terbatasnya waktu dan tempat, media sosialmampu memberikan kemudahan akses informasi dengan satu klik dan menjadi bagian dari generasi milenial dan generasi $\mathrm{Z}$ menampilkan dan mencari identitas diri dalam ruang publik.

Merujuk pandangan Clayton ${ }^{16}$ lalu bagaimana dengan situasi terkini saat era disruption ${ }^{17}$ mulai terjadi di dunia dan di Indonesia? Posisi ulama agaknya juga bergeser, dari media massa televisi dan radio, beralih lahirnya ulama yang leluasa menampilkan dirinyadi dunia visualmedia sosial. Seperti pada tanggal 22 Agustus 2018 lalu dalam akunnya Hanan Attaki mengunggah foto-foto ketika ia memimpin shalat Idul Adha di depan sebuah Masjid Al Lathif, Bandung, Jawa Barat. Masjid tersebut ia ceritakan sebagai tempat awal ia memulai berdakwah dengan mengusung "dakwah nongkrong" dan "dakwah maen”. Tepatnya empat tahun yang lalu, ia mengenang bagaimana @pemudahijrah didirikan sebagai komunitas pemuda untuk mendorong anak muda "berhijrah" yang lebih baik. Seperti yang terlihat dalam screenshoot pada Gambar 2.

Pada bagian ini micro-celebrities dapat disebut menciptakan representasi figur milenial yang ideal. Laki-laki yang maskulin, bertanggung jawab, adalah laki-laki yang taat beribadah, dekat dengan Tuhan, rajin mengikuti kajian agama, berani menikah muda namun tetap dapat berpenampilan masa kini. Menariknya dalam caption yang diciptakan oleh akun @hanan_attaki ataupun @ pemudahijrah hampir selalu menggunakan perpaduan bahasa Indonesia dengan bahasa Inggris. Seperti yang tampak di atas terdapat caption panjang

16 Clayton Christensen, The Innovator's Dilemma. (USA: Harvard Business Review Press 1st edition. 1997), hal 27.

17 Bermakna gangguan atau masalah yang dapat menghentikan aktivitas yang sudah rutin terjadi. Istilah ini dicetuskan oleh Clayton Christensen bahwa dalam bisnis perusahaan harus dapat mengantisipasi kebutuhan di masa depan, maka diperlukan persiapan akan perubahan situasi teknologi di masa depan. Disruption menghadirkan kualitas, tetapi dengan harga murah dan efisien. Dalam konteks komunikasi dan media disruption berarti perubahan cara berkomunikasi atau bermedia yang dipengaruhi perubahan teknologi, yang awalnya satu arah seperti logika media massa, menjadi multi arah seperti interaksi dalam media sosial hari ini. 
di antaranya berbunyi; "Bersama dakwah ini, saya ngerasa in this is the best part of my life gitu”. Terdapat juga kalimat "Eid Prayer Today" dan "\#ustadzchallenge", pencampuran kalimat antara bahasa Indonesia dengan bahasa Inggris ini dapat dimaknai sebagai bagian dari ambivalence ${ }^{18}$ dan ambiguity.

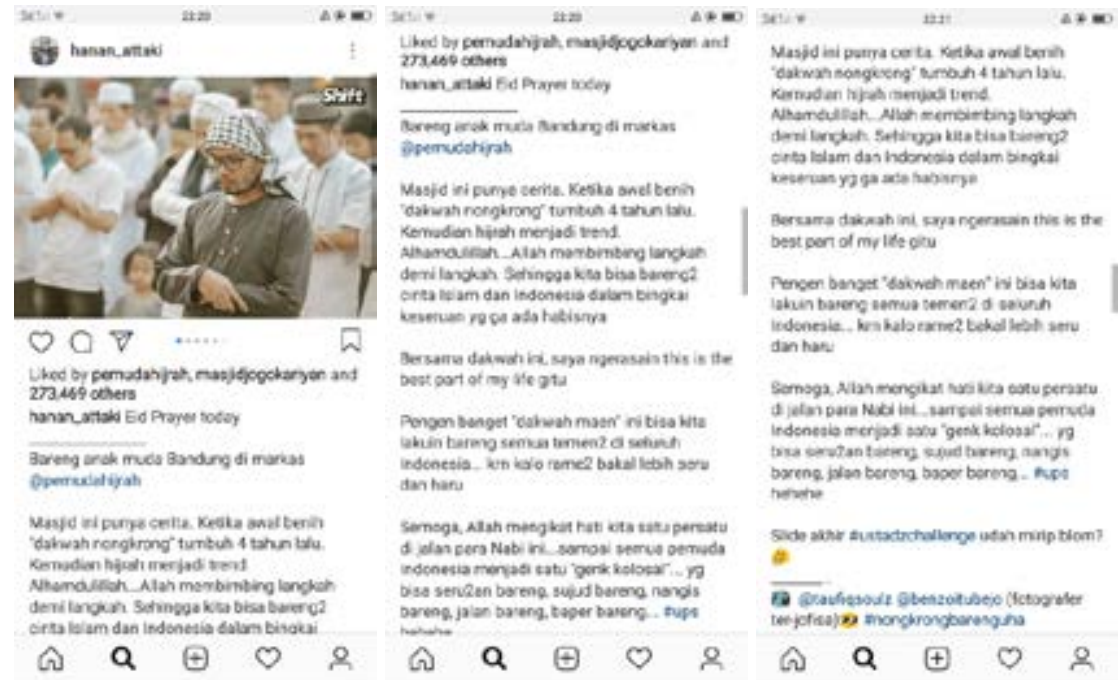

Gambar 2.Unggahan dalamakun @hanan_attaki pada tanggal 22 Agustus 2018

\section{Media Sosial: Bentuk Baru Kolonisasi Otoritas Islam}

Seperti dijelaskan oleh Homi K. Babha ${ }^{19}$ bahwa tekanan dari kekuasan kolonial sebenarnya dapat muncul dengan berbagai reaksi. Salah satunya adalah perasaan membenci sekaligus mengakui, mencintai pihak-pihak yang mengkoloni secara tidak sadar, sehingga menghasilkan perilaku-perilaku tertentu. Dalam satu sisi "ulamaonline” semacam @hanan_attaki sering kali gegabah mengartikan komunisme, liberalisme dan kapitalisme dalam unggahannya. Namun, dengan leluasa justru menggunakan bahasa asing yang erat dengan nilainilai tersebut. Bukankah dengan menggunakan media sosial Instagram dalam mengkampanyekan ide-idenya, sesungguhnya mereka sedang terlibat langsung dalam praktik kapitalisme. Kelompok-kelompok ini sering melawankan secara

18 Perasaan kontradiktif antara menyukai dan membenci pada saat yang sama. Menurut Homi Bhabha perasaan ini terjadi karena ada interaksi yang tidak dapat terelakkan antara penjajah dan yang dijajah. Kaum yang dijajah membenci perilaku penjajahan yang mengeksploitasi, namun diam-diam mengagumi penjajahnya dan ingin menjadi bagiannyadalam waktu yang sama.

19 Bhabha, Homi K, The Location of Culture. (London: Routledge, 1994), hal.45. 
oposisi biner makna-makna komunisme, liberalisme dan kapitalisme dengan Islam, Palestina dan hijrah sebagai entitas yang seolah-olah hitam putih semata. Palestina dan Suriah kerap digambarkan sebagai medan perjuangan melawan nilai-nilai dari negara "Barat", hal tersebut sering disampaikan dalam akunakun hijrah. Padahal jika ditelisik secara lebih mendalam, persoalan Palestina, Suriah misalnya, sudah terlalu kompleks permasalahan di dalamnya, baik secara politik, ekonomi, bahkan dapat dikatakan tidak ada hubungannya dengan [identitas] Islam. Reduksi terhadap permasalahan politik Palestina dengan Israel yang sudah puluhan tahun terjadi ini sangat membahayakan bagi generasi muda Islam ke depan jika tidak ada penjelasan lebih terang mengenai apa yang terjadi sesungguhnya. Jangan sampai di mata generasi Milenial dan gen $Z$ hal ini tereduksi seakan-akan pertikaian antara Yahudi versus Islam semata.
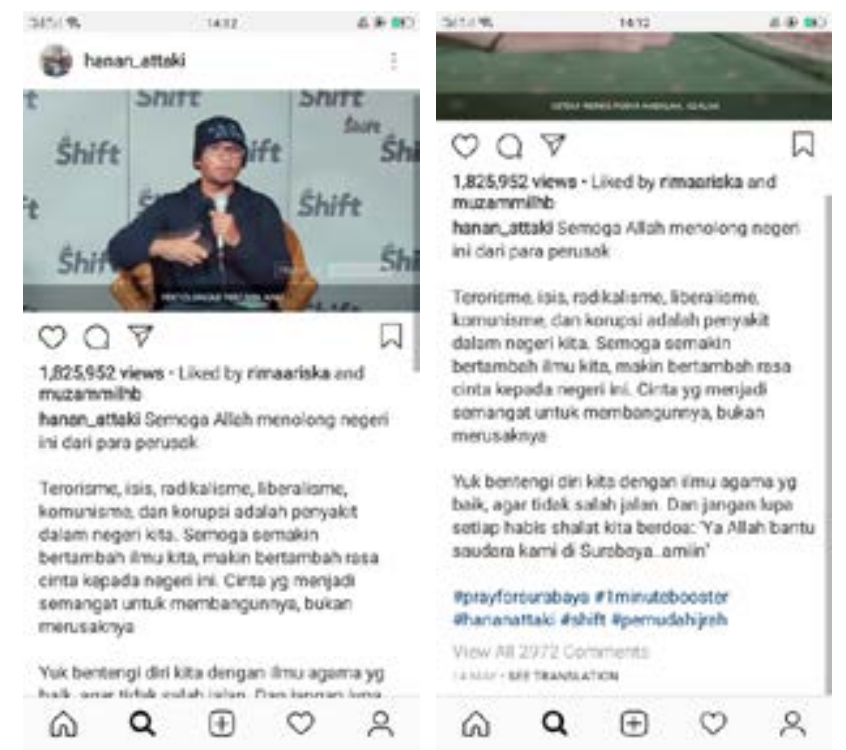

Gambar 3.Penjelasandalam @hanan_attaki atas respon bom gereja di Surabaya Mei 2018

Salah kaprah mengenai pemaknaan ini kemudian didukung dengan gambargambar yang juga diunggah bersamaan dengan penjelasan dalam akun mereka. Seperti peristiwa bom Surabaya yang terjadi pada bulan Mei 2018 lalu kemudian dijadikan bahan unggahan Hanan Attaki. Namun ia melakukan penyederhanaan makna yang sebenarnya tidak ada keterhubungan satu sama lain. Seperti captionyang berbunyi liberalisme dan komunisme yang tidak memiliki penjelasan apa kaitannya dengan bom gereja di Surabaya. Dalam silogisme bahasa justru Hanan Attaki sedang menyamakan makna terorisme, 
ISIS, radikalisme, liberalisme, komunisme dan korupsi pada nilai-nilai yang kurang lebih sama, dan yang paling penting Islam menjadi solusi dari segala nilai-nilai yang dianggap merusak itu tadi.Kelalaian yang tampak justru absennya penjelasan siapa yang disebut terorisme? Apa itu liberalisme, kapitalisme dan apa hubungannya dengan korupsi? Tidak didiskusikan secara lebih mendalam dan terinci.
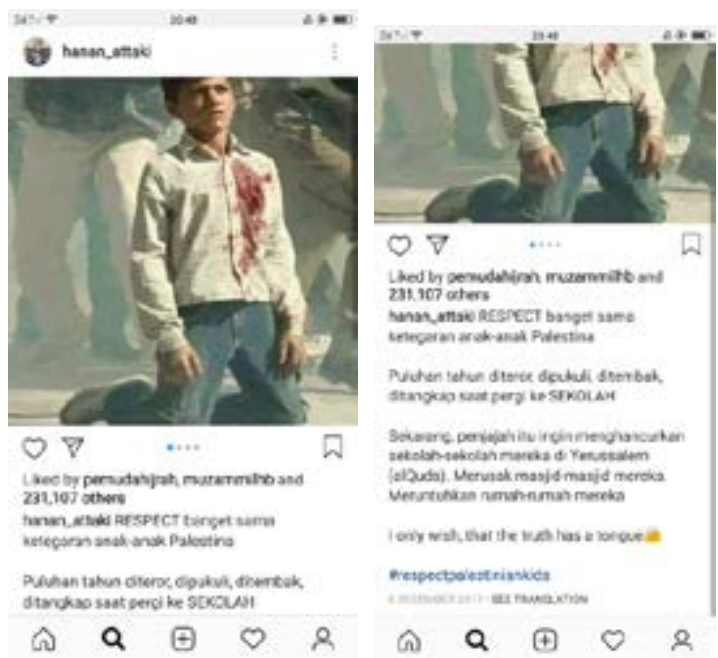

Gambar 4. Pembelaan atas negara dan rakyat Palestina sebagai simbol perlawanan Islam dengan Barat

Begitu pula "Kinerja tubuh" micro-celebrities dapat dianalisis karena mereka membangun keindahan, kebaikan Islam dan mengonstruksi kesalehan melalui unggahan gambar, video, caption, dan membuka ruang interaksi setiap hari melalui akun media sosial mereka. Hanan Attaki sering diperlihatkan duduk dalam kursi berada posisi lebih tinggi daripada jamaah masjid yang duduk bersila di lantai masjid. Dengan membawa mic dan memberi ceramah kajian Islam dalam sebuah mimbar masjid menekankan posisinya sebagai "ulama” yang dikonstruksikan sebagai "penguasa pengetahuan” agama. Dengan demikian ia memiliki otoritas atas interpretasi-interpretasi Islam dan membagikannya kepada jamaahnya. Dalam kolom komen kemudian para pengikut akunnya banyak memberi apresiasi dengan memuji, bertanya atau meminta Hanan Attaki untuk mengisi pengajian di kota asal mereka. Interaksi inilah yang disebut para micro-celebrities berhasil membentuk publik Islam mereka. 
Pesan-pesan Islam diproduksi secara besar-besaran oleh para micro-celebrities' yang menampilkan positioning diri Islam sebagai bagian dari identitas mereka. Konfigurasi ini menjamur di Indonesia khususnya pada ruang media sosial Instagram. Masih menurut Susie, Lawrence dan Raymond ${ }^{20}$ sejak awal tahun 2000 konvergensi teknologi mengubah posisi seseorang menjadi agen mandiri yang menciptakan branding dirinya, bahkan bagi orang biasa sekalipun;

"From theearly 2000s, self-branding was practised not just by those for whom a strong public image was expected (such as sports people, professional musicians and such) but also by 'ordinary' people who had shrewdly gauged the marketing possibilities of contemporary convergent technologies, particularly social media”.

Hal yang menarik kemudian adalah bagaimana bingkai Hijrah itu di konstruksikan dan dimaknai oleh para micro-celebrities ini. Melalui tampilan simbolik, hijrah dimaknai sebagai cara menghadapi hidup yang rumit dengan cara-cara Islami. Salah satu cara tersebut adalah dengan menikah muda. Dalam akun@natta_reza micro-celebrities populer yang lain misalnya mengkonstruksikan pernikahan muda adalah salah satu bentuk kesalehan. Hijrah dengan menikah dimaknai sebagai perlawanan terhadap hawa nafsu dalam menghindari zina. Seperti tampak dalam unggahannya bersama Muhammad Alvin Faiz yang memiliki pengikut satu juta dan Larissa Chou dengan pengikut 165 ribu, mereka adalah pasangan micro-celebrities' yang juga menjadi pioneer nikah muda di media sosial.

Natta Reza adalah seorang pemuda kelahiran 1999 yang awalnya berprofesi sebagai pemain band. Kemudian dalam perjalanannya mengaku tersesat dan kehilangan pegangan hidup. Disitulah ia mengaku mengalami titik balik dan memutuskan untuk “Hijrah”. Menariknya lagi-lagi dalam akun @natta_rezaia mengaku bertemu dengan istrinya yaitu @wardahmaulina_melalui Instagram. Melalui perkenalan direct messenger yang merupakan bagian dari fasilitas Instagram mereka kemudian bersepakat untuk melakukan taaruf selama dua bulan, lalu akhirnya menikah ${ }^{21}$. Menyerukan menghindari zinah dengan menikah muda, menjadi komoditas yang marak di dengungkan oleh akun-akun micro-celebrities semacam ini.

20 Susie Khamis, Lawrence Ang \& Raymond Welling. "Self-branding, 'micro-celebrity' and the rise of Social Media Influencers" dalam Celebrity Studies, Vol.8, No. 2, (UK: Routledge), hal. 195.

21 https://www.idntimes.com/hype/entertainment/stella/kisah-natta-reza-selebgram-menikahtanpa-pacaran-yang-curi-perhatian/full 

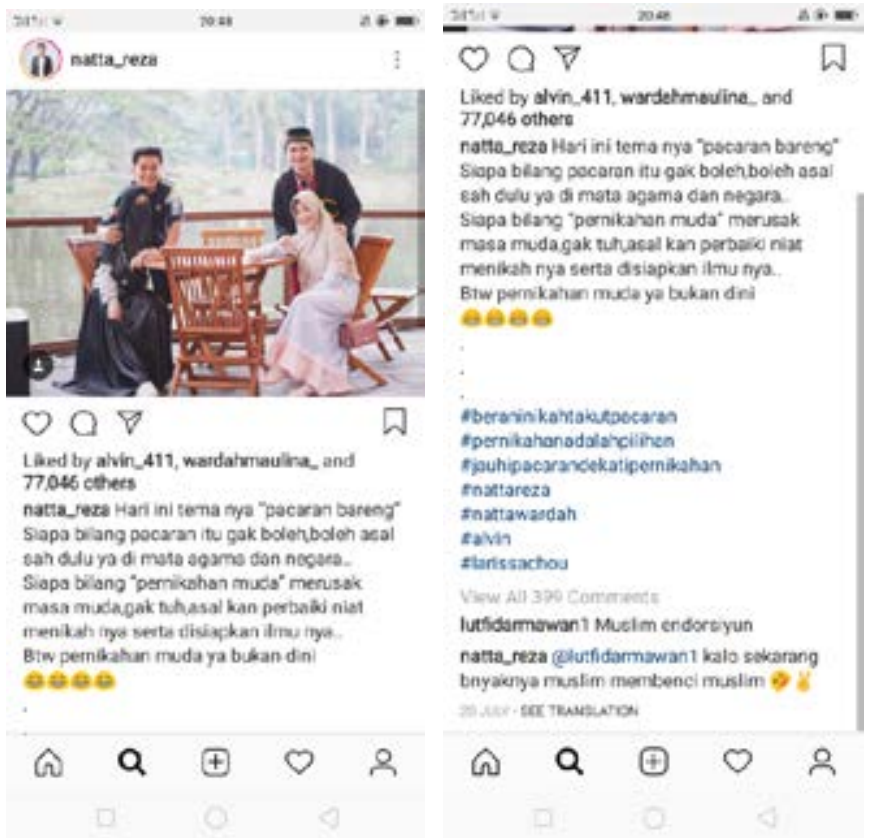

Gambar5.Akun@natta_reza salah satumicrocelebrities pelopor Hijrah dengan menikah muda

Dengan pengikut masing-masing 772 ribu dan 775 ribu akun @natta_reza dan istrinya @wardahmaulina_aktif melakukan endorsement produk-produk komersial. Konsumsi atas produk-produk "Islam" kemudian menjadi bagian dari pemasukan micro-celebrities ini mendulang pundi-pundi rupiah. Bukan itu saja, dengan menulis buku Cinta tak Biasa pasangan ini aktif memberikan motivasi "berhijrah" dengan menikah muda dan berkeliling ke kota-kota di seluruh Indonesia. Muda, Muslim, berani berhijrah dan populer kemudian menjadi kontruksi ideal mengenai micro-celebrities muslim hari ini. Satu sisi Islam semakin menuju populism yang di dalamnya mengandung ambivalensi tersendiri. Selalu menyerang "Barat" dengan statemen-statemen yang tidak disertai data dan fakta ilmiah serta kejujuran, sementara pada bersamaan para micro-celebrities ini menggunakan tools "Barat" seperti liberalisme dan sekulerisme, untuk meraup keuntungan ekonomi dengan menggunakan identitas Islam. 


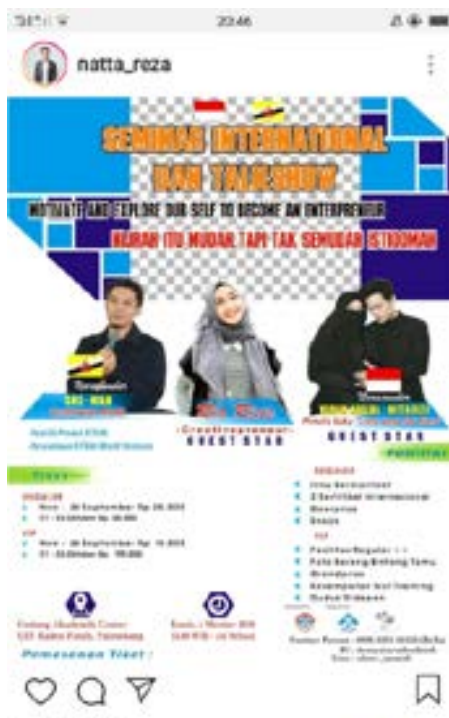

6,075 likes

natta reza Asselarrualaikum.wt.mb... S. S B.smillah info bermanfast nh ouvs anter
Sit: $2016 \quad 2.0$

Semina And Taksshow Internasional Indonesia - Brunei Darusallam

Thene : "Motivate And Explore our self to become And Entrepreneur

AND TALKSHOW " berani Hilath itu baik, hilirah the mudeh tagi tak semudah lst qomah"

Beesama Speaker luar Biasa And Guest star $\rightarrow$ Ria Ricis - Artis

Youluber -Creativeptencur - Natra Reza. Warcan Moulina - penulis bưu Cinta yang tak biasa - Penyami (Pasangan Muda yano bust anak muda laper) = Che Man - Traine: Motivator Entrepreneur - Usahawan Brunei darusallam

TKKETH Roguler:

Now - 20 segtember Rp. 35000

21 sectembet - 03 cklober Rp. 50,000

\section{VIP.}

Now- 20 segtember $R D, 75.000$

21 september - 03 oktober Rp. 100000

Lokasi. Z Kamis, 04 oktober 2018

a Gedung Aksdemik Center UIN faden Fotah PALEMEANG (C Pukul 1300 sid selesa: FASILTTAS REGULER - 2 sertif kat internasional temen ban - imu bermanfast - Doorprize . Snack
$\Omega$
a

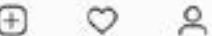

areil $\Delta+a$

ternen baiu - Inu bermenfast - Doorprize Snack

FASILITAS VIP - fost tos Reguler +H

Foto bereng Guest Stat

- Grandorize-kesempaton kut training SEMINAR BERGAPANSI TIDAK DAPAT IDMU BERMANFAAT LANG KFMBALI 100\% *

Ayo mahasiswa manfaatkan moment ini, carliah imu tanpa batas, ilmu bisa didapatkan Jari muna gajo.... Ikoti acaronyo.. Paih

Imumyo... Dapetnya Sert Sikat nya untuk nambah ktedit Point. . 'Sesuai tema Entrepreneur. Mari kita. Memotivasi dan jolajail din kita untuk menjadi pengusana. Jadilah manosiswo berkarya Tarpa batas. Jangan jod kan stotues mahasiswa penghambatmu untuk berkarya...

Dan mari keep isticomah untuk hijrà kejalan yang lebih baik. .

DITUNGGU YA GUYS... KEHADIRANENYA..- OPEN RESELLER-

info pernesanen dan reseller hubung Narna : DWa: Teip

Vees All Bo comment?

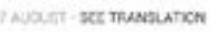

A $\quad \oplus \quad 0 \quad 8$

Gambar6.Akun@natta_reza menawarkan acara seminardan talkshow dengan judul "MotivateandExplore Our SelftoBecomeandEntrepreneur"

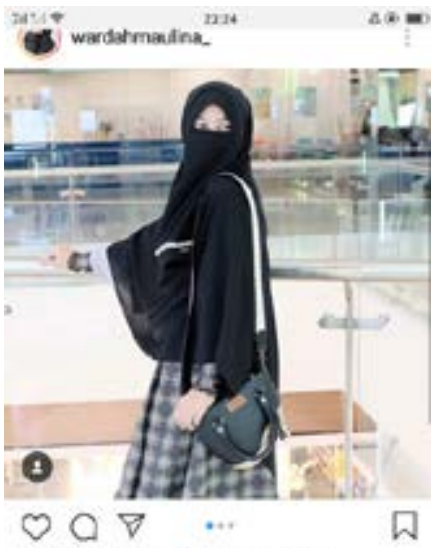

Liked by rossarere and 23,014 others

wardahmaulina. Seneng bangot kolsu ada karya anak basgasa yang lucu lucu dan unik 6 ini tas yeng supes duper lucu des:

Pkelomkennedy * suba berget sama modelnya gemassas. ty

View Af Ge Cormants
Q Q
$\oplus$
08

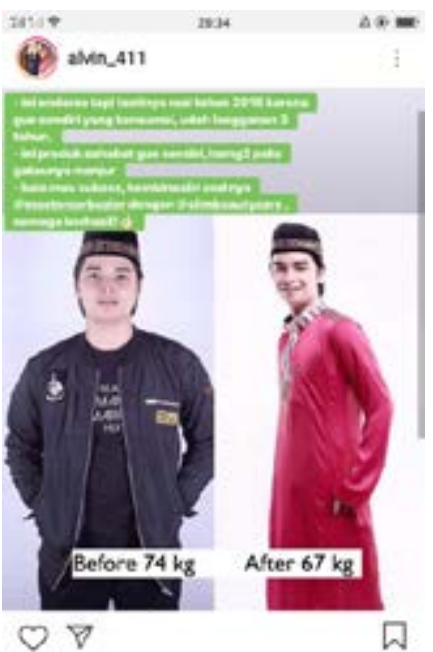

1,900 akes

atvin 111 Scosium don cecusat mongkonsumsi psimbeautycare $\cdots$

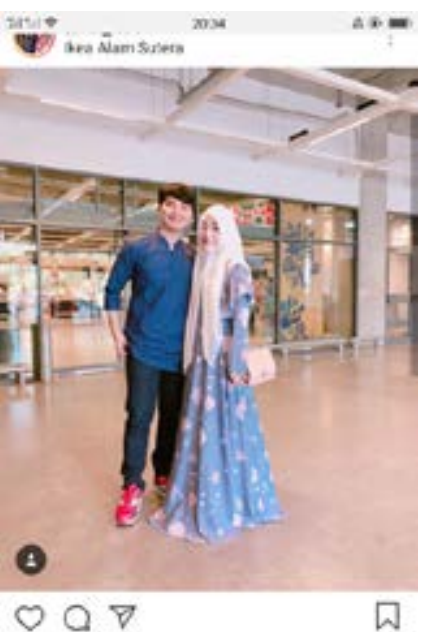

Liked by yuri_syahk_aceh and 61,369 cthers olvin-411 Teday is a good cay for the tluce! Ease stip kng thin by Gakalundonecis

Gambar 7. Micro-celebrities aktif melakukan endorsement produk dalam akun mereka 
Microcelebrities menggunakan kemampuan dalam mengakses pengikutnya dengan legitimasi pengetahuan agama [Islam], sekaligus pasar potensial. Hal ini didukung pula dengan akun-akun yang bertebaran di media sosial mengatasnamakan seperangkat pengetahuan atas nama hijrah. Melalui visualitas perempuan berhijrah misalkan dikonstruksi menggunakan jilbab yang disebut syari'i, berjilbab besar, memakai cadar (dianggap lebih baik), pakaian panjang berbentuk rok tidak membentuk tubuh dan yang paling penting bersuami atau setidaknya siap menikah. Seperti yang tampak dalam akun@akuberaniberhijarah dengan 174 ribu pengikut berikut.

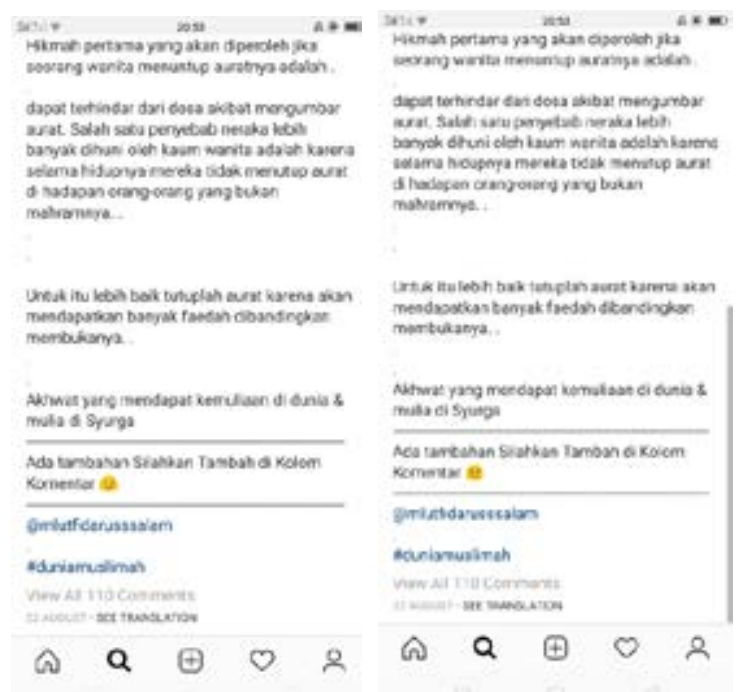

Gambar 8. Visualitas perempuan yang juga disebut akhwat "ideal" dalam berpenampilan ketika telah "berhijrah"

Merujuk pada Benjamin ${ }^{22}$ mengenai konsep aura ${ }^{23}$ adalah artefak budaya yang dapat dirusak oleh reproduksi mekanik. Benjamin juga menjelaskan aura adalah sensasi unik dari objek yang tidak dapat direproduksi. Kapitalisme memungkinkan hilangnya aura karena obyek yang diproduksi secara massal. Apabila dihubungkan dengan media sosial yang kemudian dengan masif mereproduksi pesan-pesan agama, maka yang terjadi tidak lain adalah hilangnya kesucian agama yang diproduksi dan dijajakan secara masif. Berkelindannya agama dengan kepentingan microcelebrities, ulama online, dan kapitalisme

22 Walter Benjamin, Illuminations. (New York: Schocken Books, 2007), hal.222.

23 Atmosfer atau kualitas khas yang tampaknya mengelilingi dan dihasilkan oleh seseorang, benda, atau tempat. 
akan melahirkan bias, kedangkalan dan kesalahpahaman tafsir. Inilah yang justru membuat "aura” agama kehilangan nilai. Karena mudahnya berhijrah yang kemudian menjadikan tumpang tindihnya antara kepentingan agama [Islam], ekonomi dan popularitas. Namun melalui tesis ini juga justru menjadi pembuktian bahwa sekulerisme tidak akan pernah bisa hilang dalam masyarakat Indonesia karena meskipun menguatnya identitas Islam, namun ia tetap dalam memerlukan kapitalisme sebagai ruang "menjajakan” simbol-simbol Islam.

\section{Kesimpulan}

Islam menjadi bagian suci yang seharusnya diamini sebagai jalan hidup yang jauh dari hingar bingar popularitas. Namun, hari ini siapapun dapat mengkonsumsi pesan apapun yang ia sukai berdasarkan preferensi politik, ekonomi, keyakinan, nilai budaya, maupun sosial. Sebaliknya pula siapapun dapat memproduksi tafsir-tafsir Islam yang bisa saja gegabah dalam proses interpretasi, dangkal dan miskin toleransi. Setidaknya agama dalam diskursus micro-celebrities yang tumbuh di Indonesia hari ini menunjukkan hal tersebut. Hijrah masih dimaknai sebagai perpindahan cara berpakaian, menikah tidak menikah, dan terkesan abal-abal dengan segala ornamen artifisial yang ada di dalamnya. Perdebatan tafsir, kemandirian bangsa dalam kompetisi global tampaknya tidak muncul dalam pergulatan batin "ulama online" hari ini. Karena yang simbolik lebih mudah dijajakan, lebih mudah diproduksi dan lebih mudah pula untuk dikonsumsi serta mendatangkan kapital ekonomi dengan cepat dan banyak. Hal ini yang terlihat melanda kaum mileneal yang masih terlihat "ketakutan" dalam jargon budaya "barat" yang dianggap identik dengan seks bebas, atheism, kapitalisme atau liberalisme tanpa adanya diskusi dan pemahaman yang mendalam dan komprehensif.

Di lain pihak justru melalui penggunaan media sosial mileneal dan generasi $\mathrm{Z}$ masuk dalam bentuk-bentuk pemujaan dogma agama yang lemah argumen dan mendukung praktik konsumsi atas nama kesalehan. Fungsi institusi agama [Islam] yang dahulunya formal, terkontrol, dimediasi ruang media massa yang bersifat satu arah berubah menjadi menyebar. Power yang menyebar ini bisa menjadi counteratas pemahaman normatif yang bisa saja sebelumnya memang menguntungkan penguasa negara atau ulama mainstream. Namun bila ditelisik lebih lanjut, ada pula konsekuensi lain seperti yang terjadi saat 
ini. Penyebaran otoritas pengetahuan semakin terjadi dalam segmen-segmen kecil, yang justru sulit dikontrol dan justru dapat menjadi embrio fanatisme, intoleransi, radikalisme, bahkan terorisme, karena hanya menghadirkan agama [Islam] secara hitam putih yang sekali lagi miskin argumentasi, refleksi, dan kontemplasi.

\section{Daftar Pustaka}

Abuza, Zachary. Political Islam and violence in Indonesia. London: Routledge. 2007

Baudrillard, Jean. The Precession of Simulacra. In Media and Cultural Studies: Keyworks. Meenakshi Gigi Durhamand Douglas M. Kellner (eds). Malden, Massachusetts: Blackwell Publishing. 2006

Baym, Nancy K. Baym., \&Boyd, Danah. Socially Mediated Publicness: An Introduction, Journal of Broadcasting \& Electronic Media 56(3), (2012): 320-329. DOI: 10.1080/08838151.2012.705200. ISSN: 0883-8151 print/1550-6878

Bhabha, HomiK. The Location of Culture. London: Routledge. 1994.

Benjamin, Walter. Illuminations. New York: SchockenBooks. 2007.

Castells, M. The Power of Identity. Chichester, England: Wiley-Blackwell. 1997.

Christensen, Clayton. The Innovator's Dilemma. USA: Harvard Business ReviewPress $1^{\text {stedition. } 1997 .}$

Hasan, Noorhaidi. The making of public Islam: piety, agency, and commodification on the landscape of the Indonesian public sphere. Netherlands: Springer. 2009.

Kersten, Carool. Islamic Post-Traditionalism: Postcolonial and Postmodern Religious Discourse in Indonesia. Published online: 9 August 2014. Springer Science+Business Media Dordrecht. 2014.

Khamis, Susie., Lawrence Ang \& Raymond Welling. Self-branding, 'microcelebrity' and the rise of Social Media Influencers, Celebrity Studies, Vo.8, No.2, 2017.

Lewis, R. 2013. Modest Fashion. London: I.B. Tauris.

McQuail, D. Mass Communication Theory: An Introduction. London: Sage Publications. 1994.

Mirzoeff, Nicholas.An Introductionto Visual Culture. UK: Taylor \& Francis, Ltd. 1999.

Qodir, Zuly. Public Sphere Contestation: Configuration of Political Islam in Contemporary Indonesia. IJIMS, Indonesian Journalof Islam and Muslim Societies Vol. 1, No. 1 halaman 123-149. 2011 
Raun, Tobias. 2018. Capitalizing intimacy: New subcultural forms of micro-celebrity strategies and affective laboron YouTube. London: Sage Publication. In Convergence: The International Journal of Researchinto New Media Technologies Vol. 24, No.1 halaman 99-113. 2018

Ridho, Subkhi. "Identitas Kelas Menengah Muslim di Media Sosial: Studi terhadap Wacana Islam di Media Sosial (Instagram dan Twitter)" dalam Anne Shakka Ariyani dan A. Harimurti (eds.) Nasionalisme Di Tengah Kewargaan Budaya dan Ekstremisme Global, Yogyakarta: PuSdEP, 2018.

Internet website:

https://www.idntimes.com/hype/entertainment/stella/kisah-natta-rezaselebgram-menikah-tanpa-pacaran-yang-curi-perhatian/full

www.alvara-startegic.com
Akun Instagram:
@hanan_attaki
@natta_reza
@akuberaniberhijrah 